ARTICLE

Received 5 Jun 2013 | Accepted 12 Nov 2013 | Published 11 Dec 2013

DOI: $10.1038 /$ ncomms3924

\title{
Early dynamic fate changes in haemogenic endothelium characterized at the single-cell level
}

\author{
Gemma Swiers $^{1}$, Claudia Baumann ${ }^{1, \star}$, John O'Rourke ${ }^{1, \star}$, Eleni Giannoulatou ${ }^{2}$, Stephen Taylor ${ }^{2}$, Anagha Joshi $^{3}$, \\ Victoria Moignard ${ }^{3}$, Cristina Pina ${ }^{1, \dagger}$, Thomas Bee ${ }^{1}$, Konstantinos D. Kokkaliaris ${ }^{4, \dagger}$, Momoko Yoshimoto ${ }^{5}$, Mervin \\ C. Yoder ${ }^{5}$, Jon Frampton ${ }^{6}$, Timm Schroeder ${ }^{4} \uparrow$, Tariq Enver ${ }^{1} \dagger$, Berthold Göttgens ${ }^{3}$ \& Marella F.T.R. de Bruijn ${ }^{1}$
}

Haematopoietic stem cells (HSCs) are the founding cells of the adult haematopoietic system, born during ontogeny from a specialized subset of endothelium, the haemogenic endothelium (HE) via an endothelial-to-haematopoietic transition (EHT). Although recently imaged in real time, the underlying mechanism of EHT is still poorly understood. We have generated a Runx 1 +23 enhancer-reporter transgenic mouse (23GFP) for the prospective isolation of $\mathrm{HE}$ throughout embryonic development. Here we perform functional analysis of over 1,800 and transcriptional analysis of 268 single $23 \mathrm{GFP}+\mathrm{HE}$ cells to explore the onset of EHT at the single-cell level. We show that initiation of the haematopoietic programme occurs in cells still embedded in the endothelial layer, and is accompanied by a previously unrecognized early loss of endothelial potential before HSCs emerge. Our data therefore provide important insights on the timeline of early haematopoietic commitment.

\footnotetext{
${ }^{1}$ MRC Molecular Haematology Unit, Weatherall Institute of Molecular Medicine, Radcliffe Department of Medicine, John Radcliffe Hospital, University of Oxford, Oxford OX3 9DS, UK. ${ }^{2}$ Computational Biology Research Group, Weatherall Institute of Molecular Medicine, Radcliffe Department of Medicine, John Radcliffe Hospital, University of Oxford, Oxford OX3 9DS, UK. ${ }^{3}$ Department of Haematology, Cambridge Institute for Medical Research and Wellcome Trust \& MRC Cambridge Stem Cell Institute, Cambridge CB2 OXY, UK. ${ }^{4}$ Research Unit Stem Cell Dynamics, Helmholtz Center Munich-German Research Center for Environmental Health, Ingolstaedter Landstrasse 185764 Neuherberg, Germany. ${ }^{5}$ Wells Center for Pediatric Research, Department of Pediatrics, Indiana University School of Medicine, Indianapolis, Indiana 46202, USA. ${ }^{6}$ Institute for Biomedical Research, College of Medical and Dental Sciences, University of Birmingham, Birmingham B15 2TT, UK. * These author contributed equally as second authors. † Present addresses: Stem Cell Laboratory, UCL Cancer Institute, University College London, Paul O'Gorman Building, 72 Huntley Street, London WC1E 6BT, UK (C.P. or T.E.); Department of Biosystems Science and Engineering, ETH Zurich, 4058 Basel, Switzerland. (K.D.K or T.S.). Correspondence and requests for materials should be addressed to M.F.T.R.d.B. (email: marella.debruijn@imm.ox.ac.uk).
} 
$\mathrm{D}$ efinitive haematopoietic progenitors and long-term haematopoietic stem cells (HSCs) are thought to originate during ontogeny from a specialized subset of endothelium, so-called haemogenic endothelium $(\mathrm{HE})^{1-4}$. Arguably the strongest support for the endothelial origin of haematopoietic cells comes from recent time-lapse imaging studies that directly visualized the transition of endothelium into blood, both in vitro ${ }^{5}$ and in/ex vivo ${ }^{6-9}$. What has remained unclear, however, is at what stage during this endothelial-to-haematopoietic transition (EHT) cells actually change their fate and initiate the process of commitment to the haematopoietic lineage, and how this fate change is regulated at the molecular level. Addressing these and other questions will be critical to obtain a better understanding of the cellular hierarchies and the signalling and transcription factor gene regulatory networks that underlie the specification of definitive hematopoietic stem and progenitor cells. This in turn will inform the rational development of future regenerative therapies involving the efficient generation of definitive HSCs from embryonic stem cells, induced pluripotent cells or via direct reprogramming, which at present has not been possible ${ }^{10-16}$.

A major hurdle in dissecting the process of EHT has been the lack of positive fluorescent markers specific for haemogenic, but not non-haemogenic, endothelium. To obtain such a marker, we have initiated studies into the regulation of the transcription factor Runxl, which is expressed during, and critically required for $\mathrm{EHT}^{7-9,11,17-20}$. We recently identified the Runx1 +23 haematopoietic enhancer and generated transgenic mouse lines carrying a $L a c Z$ or Gfp reporter gene transcribed from the $h s p 68$ minimal promoter under the spatiotemporal control of the Runx 1 +23 enhancer $^{21,22}$. In these lines, reporter gene expression recapitulates endogenous Runx1 expression in haematopoietic sites only, where +23 -mediated reporter gene expression is comparable with expression from a Runxl-LacZ knock-in allele $^{22}$. Indeed, functional assays showed that +23 enhancerreporter expression marked most, if not all, of the emerging haematopoietic stem and progenitor cells, similar to endogenous Runx $1^{21,22}$. Importantly, we never observed reproducible +23-mediated reporter gene expression in the nonhaematopoietic embryonic sites of endogenous Runxl expression, indicating the haematopoietic specificity of the +23 enhancer ${ }^{22}$.

In the present study, we establish that +23 enhancer-mediated GFP expression (referred to as 23GFP throughout) prospectively labels all haematopoietic-fated endothelial cells. Comprehensive functional analysis of 1,800 single $23 \mathrm{GFP}^{+}$haemogenic endothelial cells and transcriptional analysis of 268 single $23 \mathrm{GFP}^{+}$haemogenic endothelial cells reveals that HE is itself highly transitory, initiating dynamic changes towards a haematopoietic fate earlier than previously recognized, two days before HSCs emerge, while cells are still part of the endothelial wall. Furthermore, initiation of the haematopoietic differentiation programme is accompanied by a previously unrecognized early loss of endothelial potential.

\section{Results}

The 23GFP transgene marks a subset of embryonic endothelium. To obtain a positive fluorescent marker for haemogenic endothelium, we generated a transgenic reporter mouse line in which the +23 enhancer of the haematopoietic master regulator Runx1 mediates the expression of GFP specifically to the haemogenic/haematopoietic sites of the developing embryo, in a spatiotemporal pattern similar to the haematopoietic expression of a Runx1-LacZ knock-in allele ${ }^{21,22}$; (Supplementary Fig. S1a-d). In these 23GFP transgenic embryos, GFP was shown to mark functionally defined haematopoietic stem and progenitor cells ${ }^{21}$. Non-haematopoietic sites of Runxl expression are not marked by the +23 enhancer ${ }^{22}$, indicative of its haematopoietic specificity. Here, we further characterized the expression of the reporterenhancer transgene in haemogenic sites by immunostaining for VE-Cadherin (VE-Cadh) expression. In addition to its reported expression in haematopoietic cells ${ }^{21,22}, 23 \mathrm{GFP}$ expression was detected in a subset of VE-Cadh ${ }^{+}$endothelial cells (ECs) of the (paired) dorsal aorta(e) in the para-aortic splanchnopleura (PAS)/ aorta-gonad-mesonephros (AGM) region, the vitelline and umbilical (VU) arteries, and the yolk sac vasculature (Fig. 1a; Supplementary Fig. S1e,f). 23GFP expression was also observed in placental vessels (Supplementary Fig. S1g) ${ }^{22}$. In this study, we mainly focused on the haemogenic sites known to autonomously generate HSCs: the PAS/AGM and VU arteries ${ }^{23-25}$ that contain a definitive type $\mathrm{HE}^{26,27}$. In the PAS, $23 \mathrm{GFP}$ expression was already prevalent in the endothelium of the paired dorsal aortae at embryonic day (E) 8-8.5, when Runx1-LacZ expression commences $^{22}$, and before endogenous Runx1 protein expression could be detected by immunofluorescence (starting laterally in the dorsal aorta from $\sim 23$ somite pairs (sp)/E9.25; Fig. 1b). The absence of other Runx1 regulatory elements and/or the lack of Runx1-specific posttranscriptional regulation could underlie the differences in onset of expression of the 23GFP reporter and endogenous Runxl. To examine whether the early onset of 23GFP in ECs reflects a biologically distinct subset, we performed genome-wide expression profiling of E8.5 $23 \mathrm{GFP}^{+}$and $23 \mathrm{GFP}^{-}$ ECs, along with the first emerging $\mathrm{CD}_{4} 1^{+}$haematopoietic progenitor cells (HPCs; Fig. 1c). $23 \mathrm{GFP}^{+}$and $23 \mathrm{GFP}^{-}$ECs were stringently gated as $\mathrm{VE}-\mathrm{Cadh}^{+} \mathrm{Ter} 119^{-} \mathrm{CD}_{4} 5^{-} \mathrm{CD} 41^{-}$, and

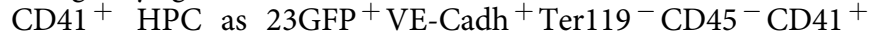
cells (Supplementary Fig. S1h). Hierarchical clustering of the expression data revealed that E8.5 $23 \mathrm{GFP}^{+}$ECs have a distinct transcriptional signature closer to the first emerging $\mathrm{CD} 41^{+}$ HPCs than to the $23 \mathrm{GFP}^{-}$endothelium (Fig. 1d). Five hundred and sixteen annotated genes were differentially expressed between the $23 \mathrm{GFP}^{+}$and $23 \mathrm{GFP}^{-}$ECs, including 45 transcription factors and 11 endothelial junction genes (Supplementary Data 1 ). The top differentially affected gene ontology processes overrepresented in $23 \mathrm{GFP}^{+}$ECs (green bars, Fig.1e) included genes associated with angiogenesis and cell migration, indicative of an active endothelial nature, and interestingly also genes expressed in response to estradiol, which was recently implicated in the formation of the hematopoietic system ${ }^{28}$. In conclusion, 23GFP expression is detected in a specific subset of the endothelium that precedes and later overlaps with endogenous Runx1 protein expression, suggesting that the 23GFP transgene prospectively identifies the HE.

23GFP ${ }^{+}$endothelial cells are haemogenic. HE has been defined as cells with an endothelial morphology and phenotype (cf. Fig. 1a,c) that form endothelial tubules in culture and are competent to generate haematopoietic progeny ${ }^{29,30}$. To examine the haemogenic potential of the $23 \mathrm{GFP}^{+}$endothelium, $23 \mathrm{GFP}^{+}$ and $23 \mathrm{GFP}^{-} \mathrm{VE}^{-\mathrm{Cadh}^{+}} \mathrm{Ter} 1 \mathrm{9}^{-} \mathrm{CD}^{-} 5^{-} \mathrm{CD} 41^{-}$endothelial cells (EC) were isolated from the E8.5 conceptus as before and from the E10.5 AGM + VU (Supplementary Fig. S2b,c) and cultured in bulk on OP9 stroma ${ }^{31}$ in conditions supporting the generation of haematopoietic progeny. Consistently, only the $23 \mathrm{GFP}^{+}$endothelium, and never the $23 \mathrm{GFP}^{-}$endothelium, gave rise to haematopoietic progeny, generating both myeloid and lymphoid cells, (Fig. 2a-d; Supplementary Fig. S2d). Haemogenic potential of the $23 \mathrm{GFP}^{+}$endothelium was more robust at E10.5 than at E8.5 (Fig. 2b), an observation further supported by limiting dilution experiments of $23 \mathrm{GFP}^{+}$endothelium at E9.5 and E10.5 (Supplementary Fig. S2e). Similar results were obtained from $23 \mathrm{GFP}^{+}$and $23 \mathrm{GFP}^{-}$yolk sac endothelium (Supplementary 

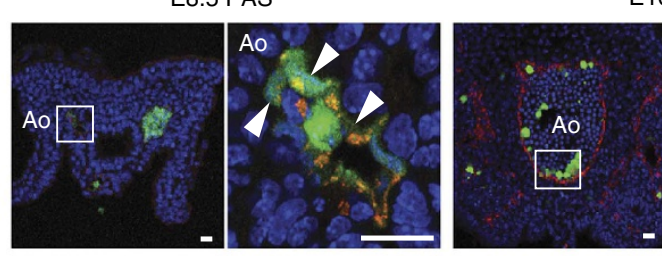

E10.5 AGM

b

E8.5 PAS

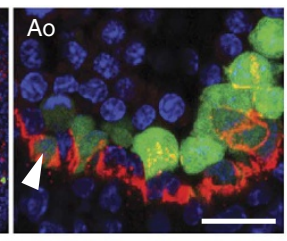

23GFP

VE-Cadh

TO-PRO-3

b

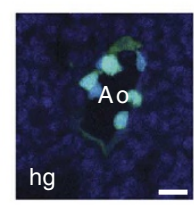

23GFP/Runx1 /TO-PRO-3

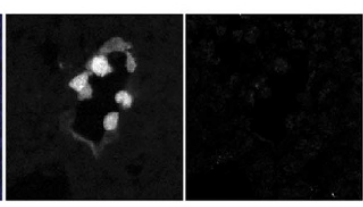

23GFP

Runx1

$10^{4}$

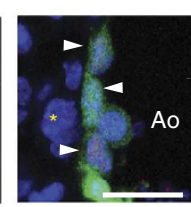

23GFP/Runx1 /TO-PRO-3

E9.25 AGM

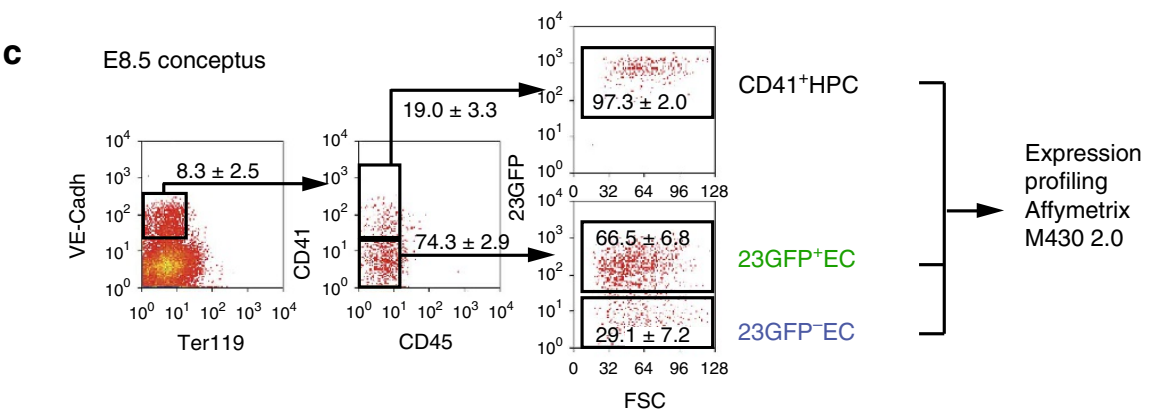

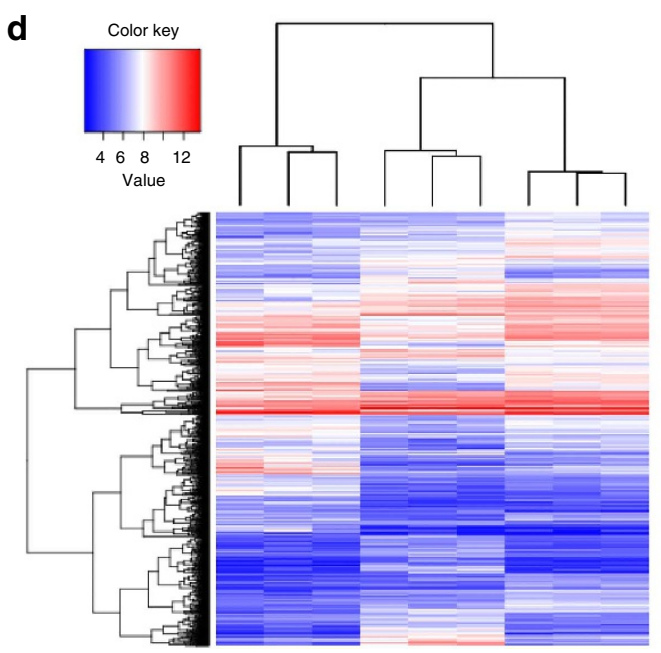

E8.5: e

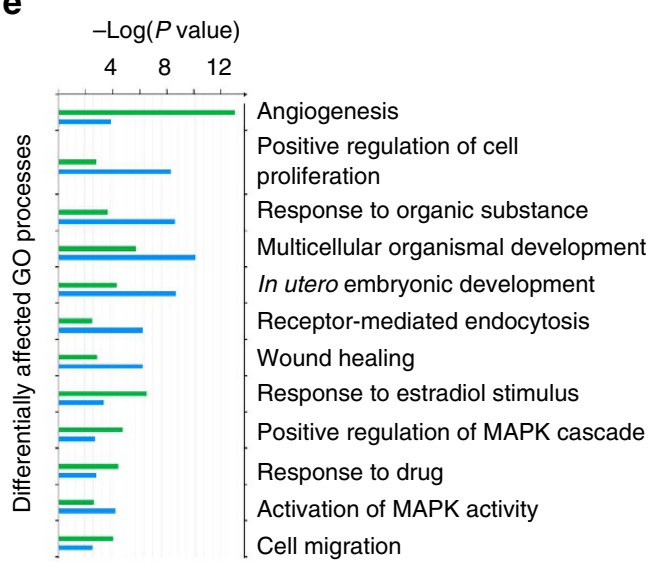

E8.5 23GFP ${ }^{+} \mathrm{EC}$

E8.5 23GFP- EC

Figure 1 | The Runx1 + 23 haematopoietic-specific enhancer marks a distinct subset of endothelium in mouse haemogenic sites. (a) VE-Cadh immunostaining (red) and 23GFP transgene expression (green) in $10 \mu \mathrm{m}$ cryosections through the posterior region of E8.5 (7-10 sp) and E10.5 (31-34 sp) 23GFP transgenic embryos. Nuclear stain (TO-PRO-3) in blue. Higher magnification images of the boxed areas show co-expression of VE-Cadh and 23GFP. Arrowhead: example of 23GFP expression in VE-Cadh ${ }^{+}$endothelial cells. Scale bar, $20 \mu \mathrm{m}$. (b) Merged and single channel images of Runx1 immunohistochemistry on 23GFP expressing sections of E8.5 (10 sp) and E9.25 (23 sp). Arrowhead: 23GFP and Runx1 co-expression, asterisk: Runx1 but no 23GFP expression. Ao, dorsal aorta; $\mathrm{Hg}$, hind gut; Vit, vitelline artery; scale bar, $20 \mu \mathrm{m}$. (c) Flow cytometric analysis further corroborates $23 \mathrm{GFP}$ expression in E8.5 (4-12 sp) VE-Cadh ${ }^{+}$Ter119 ${ }^{-}$CD 45 ${ }^{-}$CD41- endothelial cells. Representative dot plots and mean percentages \pm s.d. are from three independent analyses of pooled tissues. Sort gates are indicated. (d) Hierarchical clustering and heatmap of whole-genome gene expression data

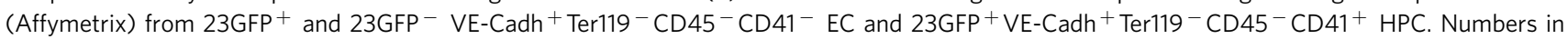
parentheses indicate the biological sample. There are 516 unique annotated probe IDs differentially expressed between $23 \mathrm{GFP}+$ and $23 \mathrm{GFP}-$ ECs (see Supplementary Data 1 for the full list). The top differentially affected GO processes overrepresented in this list are shown in (e). 
a
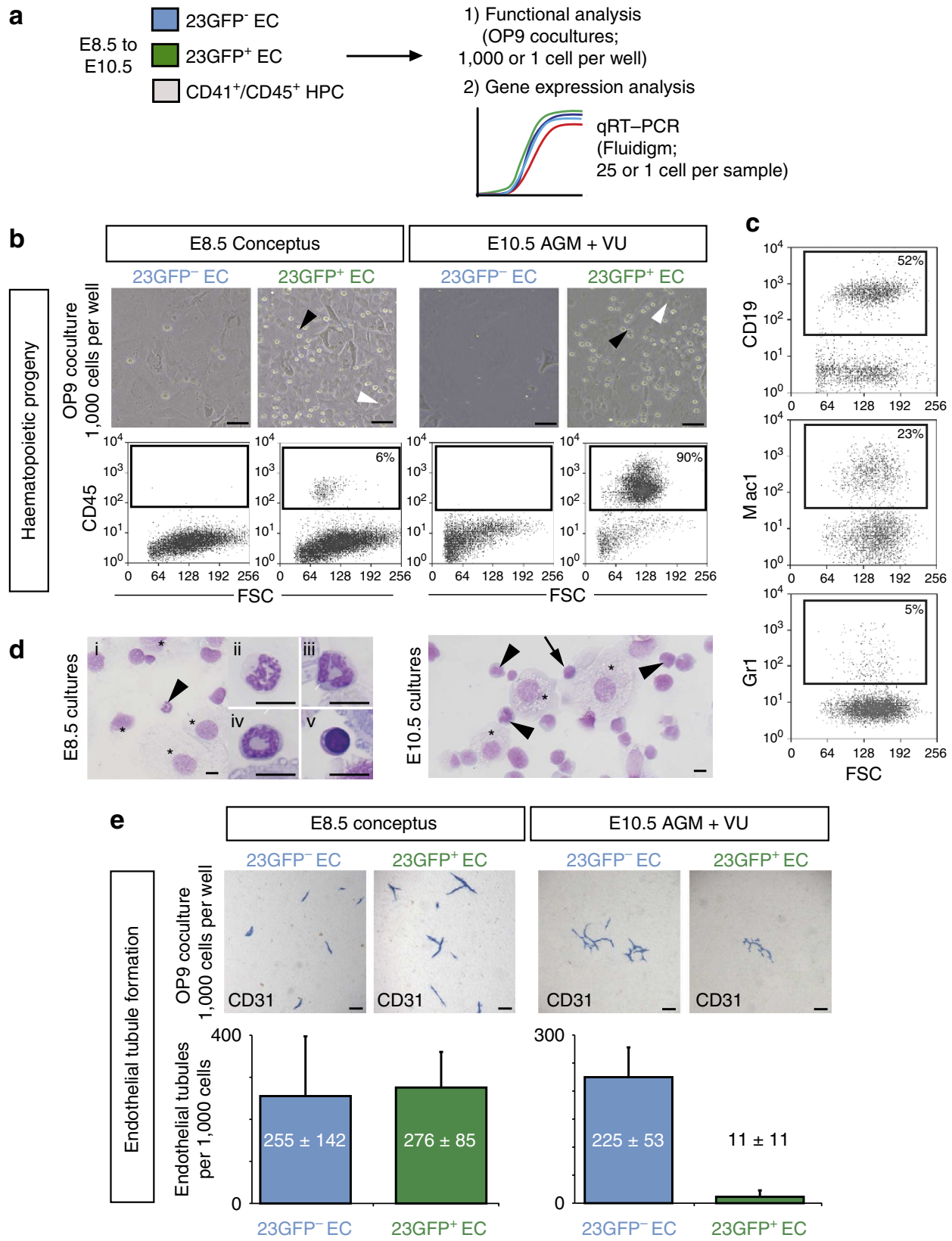

Figure 2 | Haemogenic endothelium is restricted to the 23GFP ${ }^{+}$EC population. (a) Experimental approach for data shown in Figs 2-5. (b) Generation of haematopoietic progeny by $23 \mathrm{GFP}{ }^{+}$or $23 \mathrm{GFP}{ }^{-}$VE-Cadh ${ }^{+}$Ter119 ${ }^{-}$CD45- CD41- ECs from E8.5 (5-12 sp) concepti or E10.5 (29-35 sp) AGM + VU on OP9 stroma. Black arrowhead: round semi-adherent haematopoietic cells; white arrowhead: adherent cobblestone-like cells (scale bar, $50 \mu \mathrm{m}$ ). Flow cytometric analysis confirmed the presence of $\mathrm{CD} 45^{+}$haematopoietic cells. Data are representative of at least three independent cocultures.

(c) Representative flow cytometric analysis of haemogenic cultures demonstrates both B-lymphoid (CD19) and myeloid (Mac1 or Gr1) cell generation. (d) May-Grünwald Giemsa stained cytospins of haemogenic cultures reveal myeloid (arrowhead, and ii-iv) and blast-like (arrow and v) haematopoietic cells. Asterisks point out OP9 stromal cells. Scale bar, $10 \mu \mathrm{m}$. (e) $23 \mathrm{GFP}{ }^{+}$or $23 \mathrm{GFP}{ }^{-} \mathrm{VE}-\mathrm{Cadh}{ }^{+} \mathrm{Ter}_{119}{ }^{-} \mathrm{CD}_{4} 5^{-} \mathrm{CD}_{4} 1^{-}$cells were isolated from E8.5 (5-12 sp) conceptus or E10.5 (29-35 sp) AGM + VU, and cultured on OP9 stroma to support endothelial tubule formation. Tubules were visualized by CD31 staining after 4 days of culture. Representative images and quantification (mean \pm s.d.) of endothelial tubules generated in OP9 cocultures by $23 \mathrm{GFP}^{+}$or $23 \mathrm{GFP}^{-} \mathrm{VE}-\mathrm{Cadh}{ }^{+}$Ter119 ${ }^{-} \mathrm{CD} 45^{-} \mathrm{CD}^{-} 1^{-}$cells isolated from E8.5 (5-12 sp) conceptus or E10.5 (29-35 sp) AGM + VU ( $\mathrm{n}=3$ ). Only very limited endothelial tubule formation was observed in the $23 \mathrm{GFP}+\mathrm{EC}$ population at E10.5, shown is one of 11 tubules. Scale bar, $200 \mu \mathrm{m}$.

Fig. S2f). Importantly, no significant haematopoietic clonogenic potential, indicative of the presence of HPCs rather than HE, was detected in the $23 \mathrm{GFP}^{+}$endothelial population (Supplementary Fig. S2g). In summary, these results show that throughout development, haemogenic potential segregates with the $23 \mathrm{GFP}^{+}$ endothelium, allowing for the prospective isolation of cells fated to undergo EHT.
23GFP ${ }^{+}$HE loses its endothelial potential during development. As well as the expression of endothelial markers, the ability of cells to form endothelial tubules/sheets in OP9 culture is considered a hallmark of endothelial potential and function $10,11,29,32,33$. Analysis of endothelial tubule/network formation in OP9 cocultures supplemented with vascular endothelial growth factor showed that the E8.5 $23 \mathrm{GFP}^{+}$and 
Table 1 | 23GFP + HE undergoes dynamic functional changes early in development.

No. of wells with haematopoietic and/or endothelial progeny/no. wells seeded with a single cell (frequency)

\begin{tabular}{|c|c|c|c|c|}
\hline Cell type & Stage & Haematopoietic and endothelial progeny & Haematopoietic progeny & Endothelial progeny \\
\hline \multirow[t]{3}{*}{$23 \mathrm{GFP}+\mathrm{HE}$} & E8.5 & $0 / 805$ & $0 / 805$ & $55 / 805(1: 15)$ \\
\hline & E9.5 & $0 / 540$ & $1 / 540(1: 540)$ & $8 / 540(1: 68)$ \\
\hline & E10.5 & $0 / 539$ & $11 / 539(1: 49)$ & $5 / 539(1: 108)$ \\
\hline \multirow[t]{3}{*}{$23 \mathrm{GFP}-\mathrm{EC}$} & E8.5 & $0 / 288$ & $0 / 288$ & $27 / 288(1: 11)$ \\
\hline & E9.5 & $0 / 234$ & $0 / 234$ & $13 / 234(1: 18)$ \\
\hline & E10.5 & 0/192 & 0/192 & 7/192 (1:27) \\
\hline
\end{tabular}

EC, endothelial cells, GFP, green fluorescent protein; $H E$, haemogenic endothelium; sp, somite pair.

Haemogenic and endothelial tubule forming potential of individual 23GFP $+\mathrm{HE}$ cells, as determined by clonal OP9 cocultures. Data are the total of 2-5 independent experiments performed on pooled tissues of E8.5 PAS + YS (4-10 sp), E9.25-9.5 PAS + VU (17-27 sp), E10.5 AGM + VU (32-37 sp), apart from E10.5 23GFP- cultures (1 experiment). Similar to the bulk cultures, 23GFP- EC were unable to generate haematopoietic progeny.

$23 \mathrm{GFP}^{-}$EC populations readily formed $\mathrm{CD}^{-} 1^{+}$vascular tubules and networks at an equal frequency (Fig. 2e). At E10.5, this capacity was severely reduced among the $23 \mathrm{GFP}^{+} \mathrm{ECs}$, but maintained in the $23 \mathrm{GFP}^{-}$ECs. Although a few endothelial tubules/networks were detected in cultures of $23 \mathrm{GFP}^{+}$cells, these results challenged the concept of $\mathrm{HE}$ as a bona fide endothelial cell able to generate endothelial tubules or sheets while also giving rise to haematopoietic progeny ${ }^{29}$. To explore this directly, we performed clonal cultures of E8.5 to E10.5 HE. In these cultures, a single $23 \mathrm{GFP}^{+} \mathrm{HE}$ cell never had both haematopoietic and endothelial potential (over 1,800 single cells analysed; Table 1; Supplementary Fig. S2a). Haematopoietic progeny and endothelial tubules were generated at frequencies comparable with those obtained in bulk and limiting dilution cultures, but never from the same cell ( $c f$. Fig. $2 \mathrm{e}$ and Supplementary Fig. S2e). Importantly, in line with previous reports ${ }^{5,10,29,34}$, single E7.5 $23 \mathrm{GFP}^{+}$mesodermal (Flk ${ }^{+} \mathrm{VE}-$

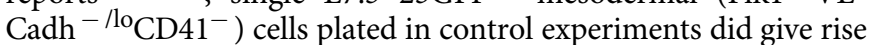
to both haematopoietic and endothelial cells, which indicates that our OP9 cultures can readout coexistence of haemogenic and endothelial potential in single cells (Supplementary Fig. S3). In conclusion, the failure to detect haemogenic and endothelial potential in a single $23 \mathrm{GFP}^{+} \mathrm{HE}$ cell indicates that if this potential exists in these cells, it is exceedingly rare, lending no experimental support for the conventional model depicted in Fig. 3. Instead, we observed that $23 \mathrm{GFP}^{+} \mathrm{HE}$ undergoes dynamic functional changes over time, showing an increased capacity to generate haematopoietic progeny, concomitant with an unexpected early decrease in endothelial potential (Table 1; Fig. 3). Importantly, this loss of endothelial potential was missed in previous studies, presumably at least in part because without a tool such as the 23GFP mice, HE could not be separated from non-haemogenic ECs.

23GFP $^{+}$HE expresses key haematopoietic and endothelial genes. To begin to analyse the molecular mechanisms that underlie the functional changes of $23 \mathrm{GFP}^{+} \mathrm{HE}$, we performed quantitative RT-PCR (qRT-PCR) on cells isolated from the E8.5 to E10.5 PAS/AGM + VU. As only few cells can be obtained from these tissues, we used the Fluidigm platform, which allows for the simultaneous analysis of multiple genes in small cell numbers. Genes coding for transcription factors affiliated with the haematopoietic lineage s5,36 were analysed on samples of 25 cells each, obtained from pooled tissues (Fig. 4). Non-haemogenic ECs and emerging CD41 ${ }^{+}$HPCs isolated from the same embryos were analysed in parallel. Strikingly, genes coding for transcription factors associated with the early specification of the haematopoietic system such as Meis1, Gata2, Gata3 and Tal1
Early onset model

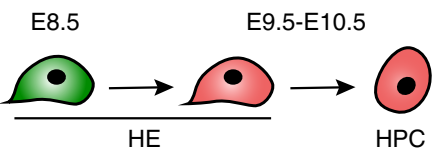

Conventional model

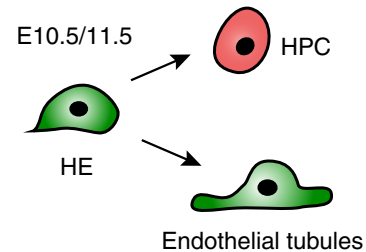

Figure 3 | Early onset model of EHT. In the conventional model of EHT (right side), haemogenic endothelium is considered as an endothelial cell capable of generating endothelial tubules and giving rise to haematopoietic progeny. This model is not supported by the functional data. In contrast, the data suggest an alternative model of EHT, with 23GFP ${ }^{+}$haemogenic endothelium undergoing an early onset of haematopoietic differentiation, and loss of endothelial potential.

$(\mathrm{Scl})$, were expressed at higher levels in $23 \mathrm{GFP}^{+} \mathrm{HE}$ than in nonhaemogenic ECs. For Meis1, Gata2, and Gata3 this was apparent already at E8.5. From E9.25, the haematopoietic master regulator Runxl was readily detected in the $23 \mathrm{GFP}^{+} \mathrm{HE}$ but not in the $23 \mathrm{GFP}^{-}$ECs. Expression of known Runx1 target genes such as Gfi1 (ref. 37) and Sfpil (Pu.1) closely followed Runx1 expression in the HE. Other haematopoietic-affiliated genes (for example, $M y b$, a marker of hematopoietic commitment ${ }^{39}$ ) also followed this pattern. Altogether, these results support a stepwise establishment of the haematopoietic programme in the $23 \mathrm{GFP}^{+}$ HE starting already at E8.5.

Single-cell analysis reveals the transitory nature of $\mathrm{HE}$. To explore the dynamics of the haematopoietic commitment process at the single-cell level at which fate changes actually occur, we isolated 268 single $23 \mathrm{GFP}^{+} \mathrm{HE}$ from E8.5 to E11.5 PAS/ AGM + VU (Table 2) and performed single-cell Fluidigm qRT-PCR for 18 haematopoietic and endothelial-affiliated genes, including 10 core haematopoietic transcription factors 35,40 . Two hundred and eighty-five non-haemogenic ECs, 212 recently emerged $\mathrm{CD} 41^{+}$HPCs, and 38 more mature haematopoietic cells, referred to as $\mathrm{CD}_{4}{ }^{+}$HPCs $\left(23 \mathrm{GFP}^{+} \mathrm{VE}-\right.$ $\mathrm{Cadh}^{+} \mathrm{Ter}_{\left.119^{-} \mathrm{CD} 41^{+} \mathrm{CD} 5^{+}\right)}$) were analysed in parallel. Principal component analysis (PCA) revealed the relationships 
between all 803 individual cells (Fig. 5a). Non-haemogenic ECs (blue) and the CD45 ${ }^{+}$HPCs (yellow) formed two clearly distinct clusters along component 1 . The endothelial genes $K d r$, Tek and the haematopoietic genes Sfpi1, Myb, Runx1, Gfi1 and Itgb3 contributed most to the separation of these cell types. In contrast, CD41 ${ }^{+}$HPCs (red) were more scattered along component 1 , indicating a continuum in maturation towards fully determined

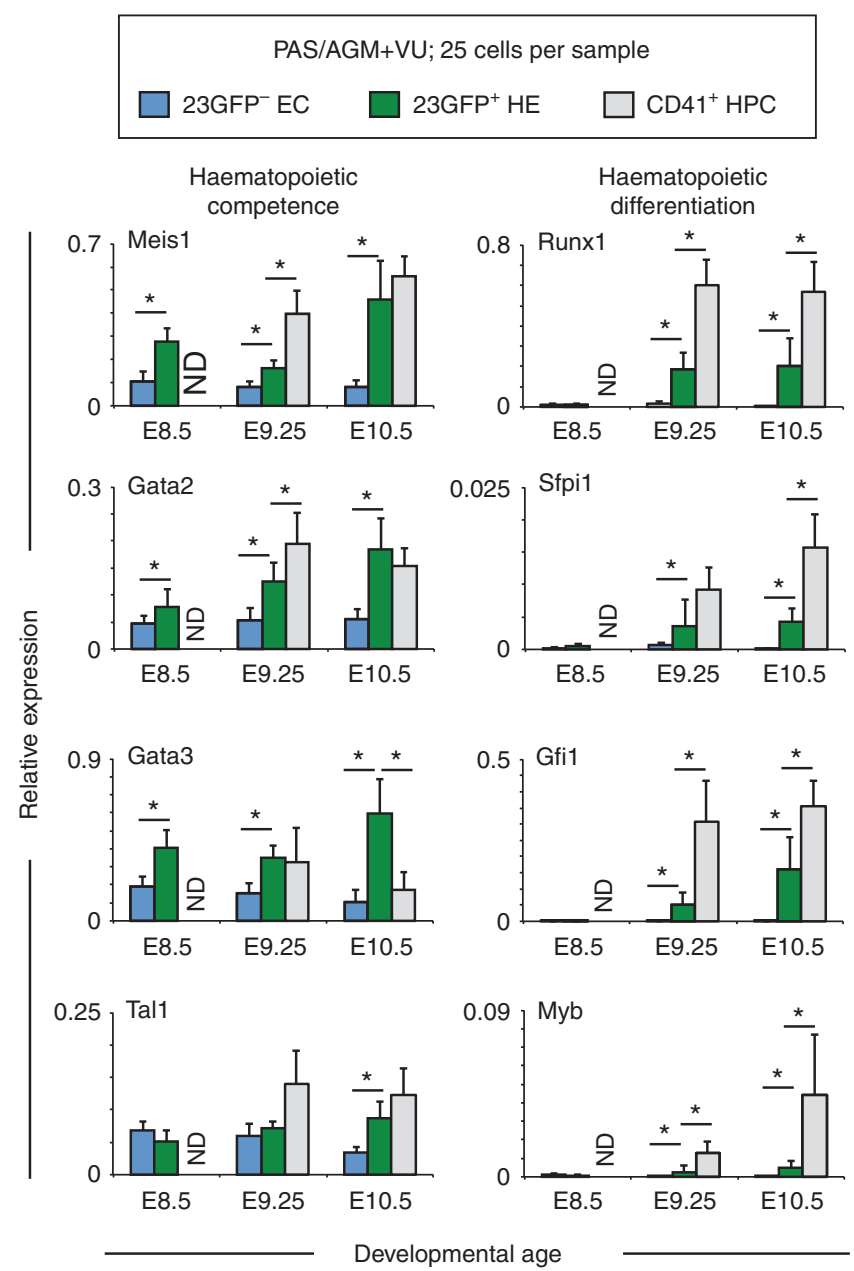

Figure 4 | Fluidigm qRT-PCR analysis of $23 \mathrm{GFP}^{+}$(green) and 23GFP(blue) VE-Cadh ${ }^{+}$Ter119- CD45- CD41- ECs and/or VE-

$\mathrm{Cadh}^{+}{ }^{-} \mathrm{Ter}_{119}{ }^{-} \mathrm{CD} 45^{-} \mathrm{CD} 41^{+}$HPCs (grey) from E8.5 (5-9 sp), 9.25 (18-22 sp), and 10.5 (32-36 sp) PAS/AGM + VU. Data are normalized to the mean of the reference genes Hprt1 and BAct and are the mean \pm s.d. of a total of 4-7 pools of 25 cells from two independent experiments. $N D$, not done. ${ }^{\star} P<0.05$ (Student's $t$-test).
CD45 ${ }^{+}$HPCs (see also the E9.5 and E10.5 PCA plots in Supplementary Fig. S4a). The $23 \mathrm{GFP}^{+} \mathrm{HE}$ cells (green) were scattered along component 1 and 2, showing increasing segregation from the non-haemogenic ECs and intermingling with $\mathrm{CD}_{4}{ }^{+}$HPCs (Fig. 5a; Supplementary Fig S4a), thus bearing out at the single-cell molecular level the dynamic functional changes observed in this transitory population over developmental time.

Analysis of gene expression on a per cell basis showed further similarities and differences between $23 \mathrm{GFP}^{+} \mathrm{HE}$ and $23 \mathrm{GFP}^{-}$ ECs. At E8.5, both the $23 \mathrm{GFP}^{+} \mathrm{HE}$ and $23 \mathrm{GFP}^{-}$EC showed stochastic, low-level sampling ${ }^{41}$ of genes associated with haematopoietic differentiation (Runx1, Gfil, Sfpil and $c-M y b)$. Moreover, both HE and non-haemogenic ECs widely expressed Itga $2 b$ (CD41) mRNA, a marker previously reported to be specific to $\mathrm{HPCs}^{42}$. After E8.5, Itga2b expression was undetectable in HE and non-haemogenic ECs, to be expressed again when cells develop into $\mathrm{CD} 41^{+} / \mathrm{CD} 45^{+}$HPCs. This unexpected ${ }^{43,44}$ early endothelial expression of Itga2 $b$ was confirmed by CD41 immunofluorescence (Supplementary Fig. S5a,b), indicating that nascent endothelium of the PAS expresses low levels of CD41. We speculate that all nascent endothelium is competent to respond to haematopoiesis-inducing signals ${ }^{45}$. Evidence of haematopoietic development was however only seen among the $23 \mathrm{GFP}^{+} \mathrm{HE}$ cells, with $\sim 50 \%$ of the E8.5 HE showing upregulation of the homeobox gene Meis1, in line with the population data ( $c f$. Figs 4 and 5b). Interestingly, this increased Meis1 (ref. 46) expression in $\mathrm{HE}$ was accompanied by a downregulation of Etv2, an Ets transcription factor expressed in early endothelial cells ${ }^{47}$ (E8.5, Fig. 5b, and see Supplementary Fig. S4b for the Pearson's correlation analysis), suggestive of a previously unrecognized antagonistic relationship between Meis1 and Etv2 in establishing the haematopoietic programme. Meis1 (as well as Gata2) expression was maintained/increased in nearly all HE cells over developmental time, contributing to their segregation from the $23 \mathrm{GFP}^{-}$ECs (Fig. 5b). Thus, it appears that only the $23 \mathrm{GFP}^{+}$ cells received and/or responded to haematopoiesis-inducing signals and have begun their journey along the haematopoietic lineage.

Haematopoietic specification of HE initiates at E9.5. In the E9.5 $\mathrm{PAS}+\mathrm{VU}, \sim 50 \%$ of the $23 \mathrm{GFP}^{+} \mathrm{HE}$ expressed the master haematopoietic regulator Runxl (Fig. 5b). Only cells with the highest Runx1 levels co-expressed known Runx1 target genes such as Sfpil and Gfil, indicating the further unfolding of the haematopoietic programme. Correspondingly, these cells showed decreased $K d r$ (Flk1) expression, establishing at the single-cell level the reported antagonistic effect of Runx1 on $K d r^{48}$ (Fig. 5b; and Supplementary Fig. S4b for Pearson's correlation analysis). $23 \mathrm{GFP}^{+} \mathrm{HE}$ from the E10.5 AGM + VU also expressed Runx1 and its downstream targets, albeit in fewer cells. Interestingly,

Table 2 | Number of single PAS/AGM + VU cells used in Fluidigm qRT-PCR analysis.

\begin{tabular}{|c|c|c|c|c|c|}
\hline $23 \mathrm{GFP}+\mathrm{HE}$ & 38 & 97 & 101 & 32 & 268 \\
\hline $\mathrm{CD} 41^{+} \mathrm{HPC}$ & NA & 99 & 113 & ND & 212 \\
\hline $\mathrm{CD} 45^{+} \mathrm{HPC}$ & NA & NA & 38 & ND & 38 \\
\hline
\end{tabular}

AGM, aorta-gonad-mesonephros; EC, endothelial cells, GFP, green fluorescent protein; HE, haemogenic endothelium; HPC, haematopoietic progenitor cells; NA, not applicable (no or very few cells present at that time point); ND, not done; PAS, para-aortic splanchnopleura; sp, somite pair; VU, vitelline and umbilical.

Number of single cells analysed in Fig. 5. Numbers are for each developmental stage and population. E8.5 (5-9 sp), E9.5 (23-28 sp), E10.5 (31-38 sp). 

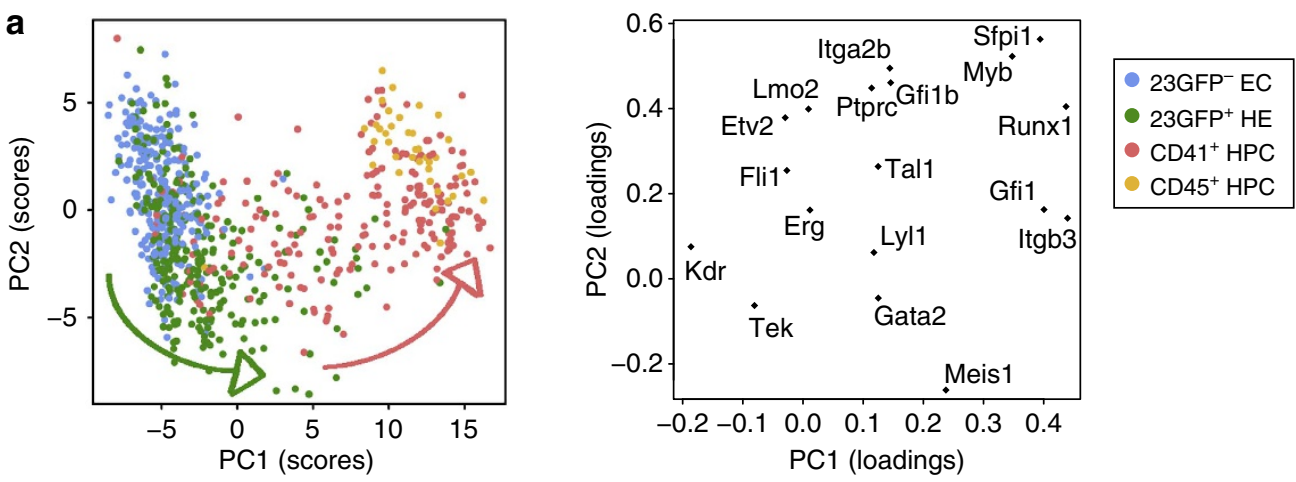

b

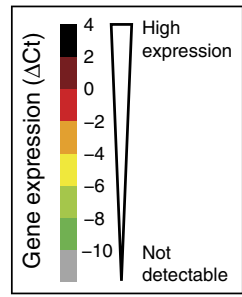

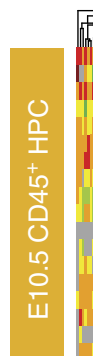
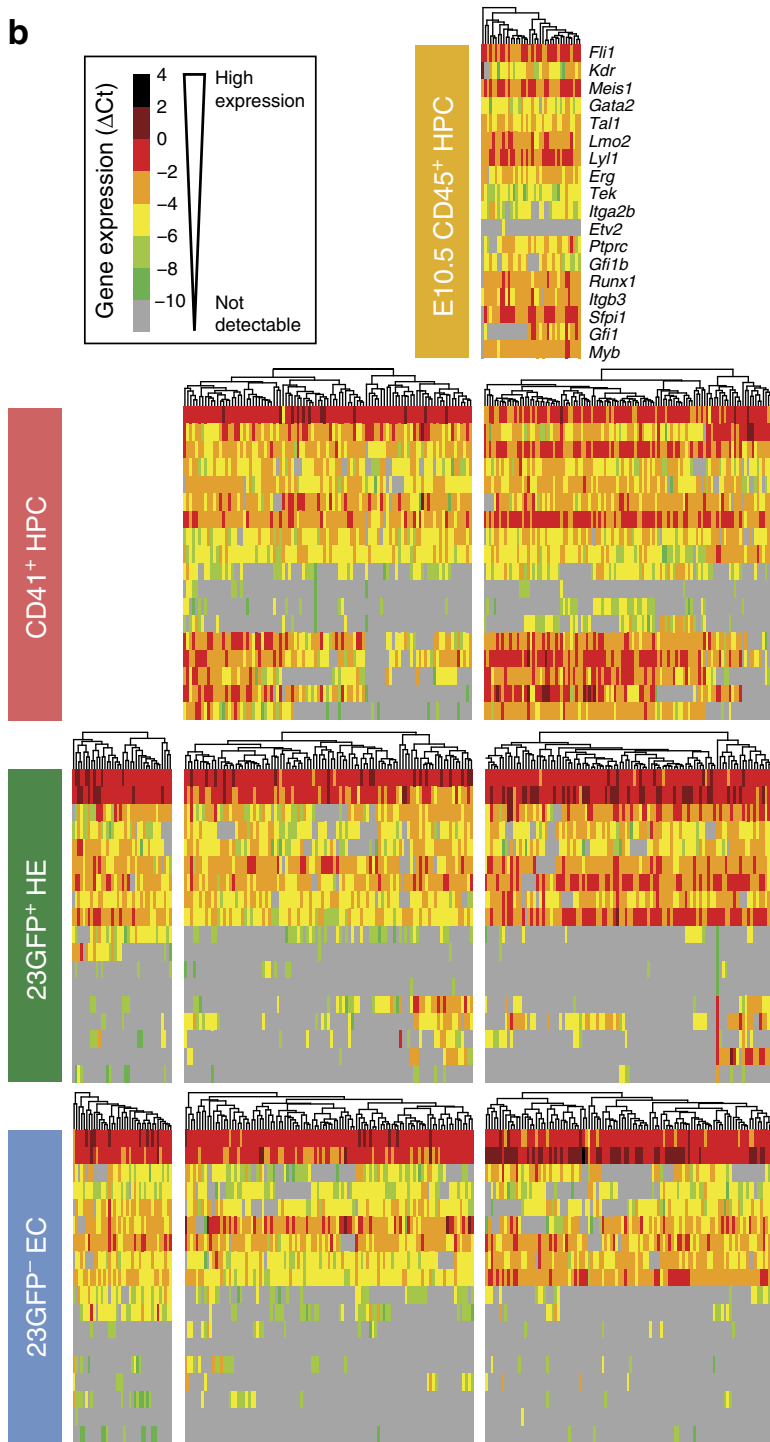

E8.5
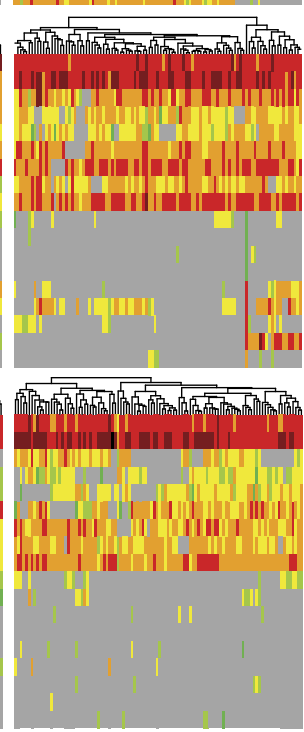

E10.5

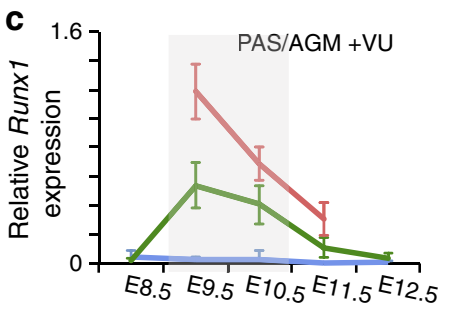

Developmental stage
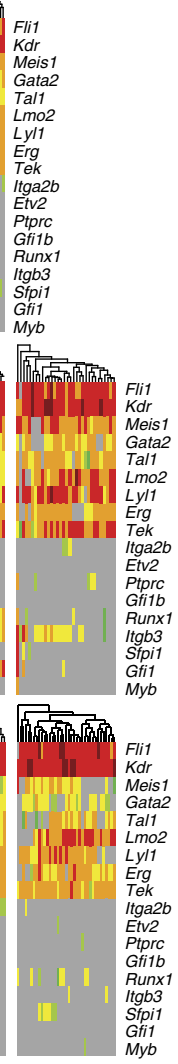

E11.5

Figure 5 | Single-cell expression analysis reveals the transitory nature of 23GFP ${ }^{+}$HE. (a) Principal component projections of all 803 cells in the first and second components. Data represent all single cells, from all time points, analysed together. Individual cells were coloured retrospectively based on the phenotype they were sorted on. Arrows indicate the direction of maturation of 23GFP $+\mathrm{HE}$ cells (green) and CD41 ${ }^{+} \mathrm{HPC}$ (red). (b) Heat maps showing the expression of the 18 endothelial- and haematopoietic-related genes in single cells for all cell types analysed. The data are $\Delta C_{\mathrm{t}}$ to the mean of Atp5a1 and $U b c$ reference genes and colour coded as $\Delta C_{t}$ steps. Columns represent individual cells, displayed after hierarchical clustering so that similar expression profiles are closer together, and rows represent the individual genes ordered based on the hierarchical clustering of all data.

(c) Narrow window of Runx1 expression in 23GFP ${ }^{+}$HE. Data are normalized to the mean of the reference genes Hprt1 and Atp5a1 and are the mean \pm s.d. of a total of 4 to 6 pools of 25 cells from two independent experiments except E12.5 (one experiment with three pools of cells). E8.5 (6-13sp), E9.5 (19-26sp) and E10.5(32-38sp). (d) Kernel density plots of the single-cell data showing increasing Runx1 levels in EC, HE and HPC at E10.5. 
Runx1 levels in HE peaked between E9.5 and E10.5 and decreased rapidly thereafter (Fig. 5b,c). As Runx1 is a critical regulator of the hematopoietic programme, this suggests that the initiation of the haematopoietic commitment process in HE, that is, the specification of the hematopoietic fate, occurs in a short burst. Never did we see any gene expression profile indicative of coordinated unfolding of the haematopoietic programme in $23 \mathrm{GFP}^{-}$cells, in line with their lack of haemogenic potential. In contrast, approximately half of the E9.5 CD $41^{+}$HPCs coexpressed Runx1, Sfpil and/or Gfil (but not yet $M y b$ ), indicative of a rapid transition of newly specified HE cells into the CD41 ${ }^{+}$ pool, also seen from the overlap between these two cell types in PCA (Fig. 5a). The rapid changes in gene expression seen upon the induction of Runx1 in HE are consistent with the model where Runx1 orchestrates the assembly of a haematopoiesisspecific pattern of transcription factor binding ${ }^{49}$. Once the cells expressed CD41, they expressed higher levels of Runx1 and its direct targets, upregulated $M y b^{39}, G f i 1 b^{50}$ and Itgb3 (CD61 (ref. 43)), and further downregulated $K d r$, reflecting progressive locking in of the haematopoietic programme and development into fully determined CD45 ${ }^{+}$HPCs (E9.5 and E10.5, Fig. 5b-d and Supplementary Fig. S4b).

\section{Discussion}

Here, we show that a transgenic GFP reporter expressed under the spatiotemporal control of the Runx $1+23$ hematopoietic enhancer allows for the positive isolation of all haemogenic cells, from mesoderm as well as the major embryonic arteries of the mouse conceptus. We have used this model to begin to understand the molecular and temporal regulation of EHT at the clonal level. To our knowledge, our study is the first clonal functional and molecular analysis of embryonic HE undergoing EHT. Combined high-throughput single cell functional and transcriptional analysis allowed us to reveal that EHT is accompanied by an early loss of endothelial potential along with a gradual unfolding of the haematopoietic programme, as opposed to a segregation of haematopoietic and endothelial programmes in a single cell. Our data show that the process of commitment to the haematopoietic lineage, consisting sequentially of specification and determination of the hematopoietic programme, is first initiated at $\mathrm{E} 9.5$ in $\mathrm{CD}_{4} 1^{-} 23 \mathrm{GFP}^{+} \mathrm{HE}$, when these cells are still part of the endothelial wall. This observation places the CD41 ${ }^{-} 23 \mathrm{GFP}{ }^{+} \mathrm{HE}$ upstream of recently identified CD $41^{\mathrm{lo}}$ pre-HSCs ${ }^{51,52}$, and it will be of interest to assess the lineal relationship between the two. In conclusion, our results re-write the concept of haematopoietic specification during EHT and have important implications for the design of future experiments aimed at obtaining a mechanistic understanding of EHT, directing the search for key haematopoietic inducing signals and critical molecular pathways to earlier developmental time points than previously anticipated. This in turn impacts on the future generation of definitive haematopoietic stem and progenitor cells from embryonic stem/induced pluripotent cells or via direct reprogramming.

\section{Methods}

Timed matings and embryo collection. For timed pregnancies, $(\mathrm{CBA} \times \mathrm{C} 57 \mathrm{BL} /$ $6) / F 1$ females (6-26 weeks old) were mated overnight with 23 GFP transgenic males (6-52 week old, maintained on a mixed $(\mathrm{CBA} \times \mathrm{C} 57 \mathrm{BL} / 6)$ background. Embryos were collected in phosphate-buffered saline (PBS; Gibco, Invitrogen) supplemented with $10 \%$ fetal calf serum (FCS; batch tested and obtained from either Biosera or PAA Laboratories), $50 \mathrm{U} \mathrm{ml}^{-1}$ penicillin, and $50 \mu \mathrm{g} \mathrm{ml}^{-1}$ streptomycin (Cambrex Corporation). E8.5 to E10.5 embryos were staged by counting somite pairs. 23GFP transgenic embryos were identified by fluorescence illumination (X-Cite 120;

Improvision) on a Leica MZFLIII microscope. Mice were housed with free access to food and water. All procedures were in compliance with United Kingdom Home
Office regulations and approved by the Ethical Review Committee of the Clinical School and the Home Office.

Dissections and generation of cell suspensions. E8.5 concepti and later stage yolk sac, PAS/AGM, VU vessels and were dissected in PBS supplemented with $10 \%$ FCS (batch tested and obtained from either Biosera or PAA Laboratories), $50 \mathrm{U} \mathrm{ml}^{-1}$ penicillin, and $50 \mu \mathrm{g} \mathrm{ml}^{-1}$ streptomycin (Cambrex Corporation) using watch makers forceps and $25 \mathrm{G}$ needles. Concepti were dissected without the ectoplacental cone, and in part of the experiments without the head and heart region. Tissues were pooled and incubated for $20 \mathrm{~min}$ at $37^{\circ} \mathrm{C}$ in PBS supplemented with $10 \% \mathrm{FCS}, 50 \mathrm{U} \mathrm{ml}^{-1}$ penicillin, $50 \mu \mathrm{g} \mathrm{ml}^{-1}$ streptomycin and $0.12 \%$ $(\mathrm{w} / \mathrm{v})$ of collagenase (Type I, Sigma), and dissociated by pipetting. Suspensions were washed, and viable cells were counted on the basis of trypan blue (SigmaAldrich) exclusion using a Neubauer haemocytometer.

Flow cytometry and cell sorting. Embryonic cells were isolated by flow cytometry using a $100 \mu \mathrm{m}$ nozzle at 30 p.s.i. and $<1,500$ events per second (MoFlow; Beckman Coulter). For single-cell qRT-PCR, cells were sorted directly using FACSAria III with an $85 \mu \mathrm{m}$ nozzle (Becton Dickinson). Analysis was performed on CyAn ADP (Beckman Coulter). Antibody staining was carried out on ice and in the dark for 15 min in PBS supplemented with $10 \%$ FCS (batch tested and obtained from either Biosera or PAA Laboratories) and $50 \mathrm{U} \mathrm{ml}^{-1}$ penicillin, and $50 \mu \mathrm{g} \mathrm{ml}^{-1}$ streptomycin (Cambrex Corporation). Cells were collected into FCS-coated tubes and recounted prior to plating where possible. Antibodies and conjugates (Supplementary Table S1) were titrated to determine their optimal concentration of use. Gates were defined using unstained, single stained and fluorescence minus onestained cells. Dead cells were excluded based on Hoechst 33258 (Invitrogen) uptake. Data were acquired and analysed using Summit (BC) or FACS Diva (BD) software.

Fluorescent microscopy. Embryos were fixed in 4\% paraformaldehyde (Electron Microscopy Sciences) for $1-2 \mathrm{~h}$ at $4{ }^{\circ} \mathrm{C}$, washed in PBS, and soaked in $15 \%(\mathrm{w} / \mathrm{v})$ sucrose for $2-4 \mathrm{~h}$ at $4^{\circ} \mathrm{C}$. Samples were snap-frozen in Tissue-Tek OCT compound (Sakura, Siemens Medical Solutions Diagnostics) and sectioned at $10 \mu \mathrm{m}$ on a Leica CM3050s cryostat, collected onto Superfrost plus glass slides (VWR) and after air drying, washed in PBS. For VE-Cadh or CD41 staining, sections were block permeated with $10 \%$ FCS in $0.05 \%$ Tween/PBS for $30 \mathrm{~min}$ at RT, incubated with purified rat anti-mouse VE-Cadh or CD41 antibody (Supplementary Table S1) in $0.05 \%$ Tween PBS for $1 \mathrm{~h}$ at room temperature (RT), followed by $2 \mathrm{~h}$ incubation at RT with goat anti-rat AlexaFluor555 antibody $\left(10 \mu \mathrm{g} \mathrm{ml}^{-1}\right.$; Invitrogen) in $2 \%$ normal mouse serum and $0.05 \%$ Tween/PBS. For Runx1 Ab staining, sections were permeated with $1 \%$ Triton X-100/PBS for 10 min at RT, blocked with $10 \%$ FCS/ PBS for $30 \mathrm{~min}$ at RT, incubated with polyclonal rabbit anti-mouse Runx1 antibody (kind gift of the Jessel lab) in 10\% FCS/PBS overnight at $4{ }^{\circ} \mathrm{C}$ and stained for $2 \mathrm{~h}$ at $\mathrm{RT}$ with goat anti-rabbit AlexaFluor555 antibody $\left(10 \mu \mathrm{g} \mathrm{ml}^{-1}\right.$; Invitrogen) in $2 \%$ normal mouse serum and PBS. Slides were stained with TO-PRO-3 iodide $(0.2 \mu \mathrm{M}$ final concentration; Invitrogen) in PBS for $20 \mathrm{~min}$, washed in PBS and coverslipped with Vectashield mounting medium containing 4',6-diamidino-2-phenylindole (DAPI, Vector Laboratories). Sections were analysed and photographed with an Olympus BX51 camera (Olympus), Radiance 2000 Confocal Scanning System (Bio-Rad), and Laser Sharp 2000 software (Zeiss). Images were processed using Confocal Assistant 3.0 (CAS) and Adobe Photoshop (Adobe systems, Europe).

Haematopoietic progenitor assay. Colony-forming unit-culture (CFU-C) assays were performed using Methocult M3434 (Stem Cell Technologies). Cells were plated in duplicate in $35 \mathrm{~mm}$ culture dishes according to manufacturer's instructions. Cultures were grown at $37^{\circ} \mathrm{C}$ with $5 \% \mathrm{CO}_{2}$ with colonies scored after 7 days

OP9 maintenance. OP9 cells (kindly provided by M. Yoder, Indianapolis) were maintained in $\alpha$ MEM (Gibco) with $20 \%$ defined FCS (Hyclone) and $0.22 \%$ sodium bicarbonate (Gibco) at $37^{\circ} \mathrm{C}, 5 \% \mathrm{CO}_{2}$. Cells were passaged every 3 days using $0.05 \%$ Trypsin/EDTA (Gibco) at $37^{\circ} \mathrm{C}$ for $6 \mathrm{~min}$. For co-culture experiments, cells were resuspended in $\alpha \mathrm{MEM}$ with $10 \%$ FCS and $1 \times 10^{-4} \mathrm{M} 2$-mercaptoethanol and plated at $23 \times 10^{3}$ cells per $\mathrm{cm}^{2} 24 \mathrm{~h}$ before the experiment.

OP9 cocultures. For single cell and limiting dilution cocultures, cells were directly sorted onto confluent OP9 stroma; for all other cocultures, cells were sorted and recounted prior to plating. Cocultures of OP9 with E7.5 cells were supplemented with $100 \mathrm{ng} \mathrm{ml}^{-1}$ SCF and grown for 5-7 days. For E8.5 to E10.5 haemogenic and single-cell assays, cultures were supplemented with $10 \mathrm{ng} \mathrm{ml}^{-1} \mathrm{IL7}, 10 \mathrm{ng} \mathrm{ml}^{-1}$ SCF and $10 \mathrm{ng} \mathrm{ml}^{-1}$ Flt-3-ligand, and incubated for $8-10$ days at $37^{\circ} \mathrm{C}, 5 \% \mathrm{CO}_{2}$. The haematopoietic nature of the cells generated in the OP9 cocultures was assessed by microscopy, flow cytometry and/or May-Grünwald Giemsa staining of cytospins. For endothelial assays, cells were cultured with $50 \mathrm{ng} \mathrm{ml}^{-1}$ recombinant murine vascular endothelial growth factor for 4 days at $37^{\circ} \mathrm{C} 5 \% \mathrm{CO}_{2}$. All cytokines were purchased from Peprotech (Supplementary Table S2). To visualize endothelial cell growth, cultures were stained with rat anti-mouse CD31 
(MEC13.3) followed by alkaline phosphatase-conjugated goat anti-rat and detected by Vectablue AP Substrate Kit III (Vector). Images were collected on an Olympus $1 \times 51$ microscope equipped with a Jenoptik ProgRes C14 camera, and processed using Adobe Photoshop.

Microfluidic Quantitative RT-PCR. Multiplex qRT-PCR was performed using the Fluidigm (Biomark) platform. TaqMan assays (Applied Biosystems; Supplementary Table S3) were pooled to a final concentration of $0.2 \times$. Cells were harvested directly into $10 \mu \mathrm{l}$ RT-PreAmp Master Mix (consisting of $5 \mu \mathrm{l}$ CellsDirect $2 \times$ Reaction Mix (Invitrogen), $2.5 \mu \mathrm{l} 0.2 \times$ assay mix, $1.2 \mu \mathrm{l} \mathrm{RT/Taq} \mathrm{enzyme} \mathrm{(Cells-}$ Direct qRT-PCR kit, Invitrogen), $1.2 \mu \mathrm{l}$ TE buffer (Invitrogen) and $0.1 \mu \mathrm{l}$ SUPERase-In (Ambion)). Collected samples were immediately vortexed and spun to aid cell lysis. Reverse transcription was performed at $50^{\circ} \mathrm{C}$ for $15 \mathrm{~min}$ and inactivated at $95^{\circ} \mathrm{C}$ for $5 \mathrm{~min}$. In the same tube, cDNA was amplified by 22 cycles at $95^{\circ} \mathrm{C}$ for $15 \mathrm{~s}$ followed by $60^{\circ} \mathrm{C}$ for $4 \mathrm{~min}$. The pre-amplified mix was immediately frozen at $-20^{\circ} \mathrm{C}$ until further analysis. Samples were diluted fivefold and analysed on 48.48 Dynamic Arrays according to manufacturers' instructions, using the following PCR conditions: $95^{\circ} \mathrm{C}$ for $10 \mathrm{~min}$, followed by 40 cycles of $95^{\circ} \mathrm{C}$ for $15 \mathrm{~s}$ and $60^{\circ} \mathrm{C}$ for $1 \mathrm{~min}$ (Fluidigm, BioMark). Amplification curves were quality filtered using a threshold $<0.65$, and $\mathrm{Ct}$ thresholds were set for each assay with the same thresholds used across all experiments. Ct values were calculated by BioMark Real-time PCR Analysis software (Fluidigm). Data were exported to Excel as.csv files for subsequent analysis.

Microfluidic quantitative RT-PCR analysis. For population level analysis, two independent sorting experiments were performed each with 2-3 biological replicates of 25 cells. Data were analysed by the $\Delta C_{\mathrm{t}} \operatorname{method}^{53}$, normalized to $H p r t 1$ and $B A c t$. For single-cell analysis, 20 haematopoietic and endothelial-affiliated genes and four housekeeping assays were analysed in duplicate with positive (20 cell) and negative ( 0 cell) controls analysed on each 48.48 array. Duplicate readings were averaged, and the data were filtered according to no template control reactions, ( 0 cell), and excluding $C_{\mathrm{t}}>27$. Genes that were not expressed were set to a $C_{\mathrm{t}}$ of 27 . All $C_{\mathrm{t}}$ values were subtracted from the no template background of 27 . Samples were included for downstream analysis based on the expression of Atp $5 a 1$ and $U b c$ with $\Delta C_{\mathrm{t}}$ values calculated using the mean Ct value of $A t p 5 a 1$ and $U b c$ for each cell. $C d h 5$ and $C b f b$ assays were not used for single-cell analysis based on poor amplification curves. Hierarchical clustering, Pearson's correlation and principal component analyses were performed in R (http://www.r-project.org) and did not include housekeeping genes.

Microarray analysis. Whole-genome expression analysis was performed using total RNA extracted using Trizol according to manufacturers' instructions (Invitrogen) and purified using RNeasy Micro kit (Qiagen). With the same total amount of input RNA, triplicate samples were amplified with a WT-Ovation Pico RNA Amplification System followed by WT-Ovation cDNA Biotin Module V2 for cDNA labelling (NuGEN) and fragmentation, and were finally hybridized to Affymetrix Mouse Genome 4302.0 arrays by standard protocols (Affymetrix) at the Stanford Protein and Nucleic Acid facility. The CEL files were normalized using RMA in the affy package ${ }^{54}$ and a threshold of log expression value of 5 in at least one sample was used for selecting informative probes. Significantly differentially expressed genes were selected using the LIMMA ${ }^{55}$ package with $>1.0$ absolute log fold change and adjusted (Benjamini Hockberg) $P<0.05$ for comparisons of $\mathrm{HE}$ versus $\mathrm{E}$ and HPC versus non-HPC samples. The union of these was then used to select probes for the heatmap generated by the gplots library (http://www.CRAN.Rproject.org/package=gplots). Gene ontology enrichment analysis and annotation of the probe sets was done using Metacore (http://www.thomsonreuters.com/ metacore/), which uses the Multicore variation of the Fisher's exact test and adjusts for multiple sample testing using FDR.

Statistics. Results, unless otherwise indicated, are expressed as mean \pm s.d. Two-tailed Student's $t$-test was used to determine the level of significance with $\mathrm{P}<0.05$ considered statistically significant and indicated by an asterisk.

\section{References}

1. Dieterlen-Lievre, F. Hematopoiesis: progenitors and their genetic program. Curr. Biol. 8, R727-R730 (1998)

2. Jaffredo, T. et al. From hemangioblast to hematopoietic stem cell: an endothelial connection? Exp. Hematol. 33, 1029-1040 (2005).

3. Medvinsky, A., Rybtsov, S. \& Taoudi, S. Embryonic origin of the adult hematopoietic system: advances and questions. Development 138, 1017-1031 (2011).

4. Antas, V. I., Al-Drees, M. A., Prudence, A. J., Sugiyama, D. \& Fraser, S. T. Hemogenic endothelium: a vessel for blood production. Int. J. Biochem. Cell Biol. 45, 692-695 (2012).

5. Eilken, H. M., Nishikawa, S. \& Schroeder, T. Continuous single-cell imaging of blood generation from haemogenic endothelium. Nature 457, 896-900 (2009).
6. Bertrand, J. Y. et al. Haematopoietic stem cells derive directly from aortic endothelium during development. Nature 464, 108-111 (2010).

7. Boisset, J. C. et al. In vivo imaging of haematopoietic cells emerging from the mouse aortic endothelium. Nature 464, 116-120 (2010).

8. Kissa, K. \& Herbomel, P. Blood stem cells emerge from aortic endothelium by a novel type of cell transition. Nature 464, 112-115 (2010)

9. Lam, E. Y., Hall, C. J., Crosier, P. S., Crosier, K. E. \& Flores, M. V. Live imaging of Runx1 expression in the dorsal aorta tracks the emergence of blood progenitors from endothelial cells. Blood 116, 909-914 (2010).

10. Choi, K. D. et al. Identification of the hemogenic endothelial progenitor and its direct precursor in human pluripotent stem cell differentiation cultures. Cell Rep. 2, 553-567 (2012).

11. Lancrin, C. et al. The haemangioblast generates haematopoietic cells through a haemogenic endothelium stage. Nature 457, 892-895 (2009).

12. Kennedy, M. et al. T lymphocyte potential marks the emergence of definitive hematopoietic progenitors in human pluripotent stem cell differentiation cultures. Cell Rep. 2, 1722-1735 (2012).

13. Ledran, M. H. et al. Efficient hematopoietic differentiation of human embryonic stem cells on stromal cells derived from hematopoietic niches. Cell Stem Cell 3, 85-98 (2008).

14. Nakajima-Takagi, Y. et al. Role of SOX17 in hematopoietic development from human embryonic stem cells. Blood 121, 447-458 (2013).

15. Szabo, E. et al. Direct conversion of human fibroblasts to multilineage blood progenitors. Nature 468, 521-526 (2010).

16. Pereira, C. F. et al. Induction of a hemogenic program in mouse fibroblasts. Cell Stem Cell 13, 205-218 (2013).

17. North, T. et al. $\mathrm{Cbfa} 2$ is required for the formation of intraaortic hematopoietic clusters. Development 126, 2563-2575 (1999).

18. Yokomizo, T. et al. Requirement of Runx1/AML1/PEBP2 $\alpha \mathrm{B}$ for the generation of haematopoietic cells from endothelial cells. Genes Cells 6, 13-23 (2001).

19. North, T. E. et al. Runxl expression marks long-term repopulating hematopoietic stem cells in the midgestation mouse embryo. Immunity 16, 661-672 (2002).

20. Chen, M. J., Yokomizo, T., Zeigler, B. M., Dzierzak, E. \& Speck, N. A. Runx1 is required for the endothelial to haematopoietic cell transition but not thereafter. Nature 457, 887-891 (2009).

21. Bee, T. et al. Nonredundant roles for Runx1 alternative promoters reflect their activity at discrete stages of developmental hematopoiesis. Blood 115, 3042-3050 (2010).

22. Nottingham, W. T. et al. Runx1-mediated hematopoietic stem-cell emergence is controlled by a GATA/ETS/SCL-regulated enhancer. Blood 110, 4188-4197 (2007).

23. de Bruijn, M. F., Speck, N. A., Peeters, M. C. \& Dzierzak, E. Definitive hematopoietic stem cells first develop within the major arterial regions of the mouse embryo. EMBO J. 19, 2465-2474 (2000).

24. Medvinsky, A. \& Dzierzak, E. Definitive hematopoiesis is autonomously initiated by the AGM region. Cell 86, 897-906 (1996).

25. Gordon-Keylock, S., Sobiesiak, M., Rybtsov, S., Moore, K. \& Medvinsky, A. Mouse extra-embryonic arterial vessels harbor precursors capable of maturing into definitive HSCs. Blood 122, 2338-2345 (2013).

26. Chen, M. J. et al. Erythroid/myeloid progenitors and hematopoietic stem cells originate from distinct populations of endothelial cells. Cell Stem Cell 9, 541-552 (2011).

27. Clarke, R. L. et al. The expression of Sox17 identifies and regulates haemogenic endothelium. Nat. Cell Biol. 15, 502-510 (2013).

28. Carroll, K. et al. 17beta-estradiol has a biphasic effect on the formation of hematopoietic stem cells. Exp. Hematol. 41, S12 (2013).

29. Nishikawa, S. I., Nishikawa, S., Hirashima, M., Matsuyoshi, N. \& Kodama, H. Progressive lineage analysis by cell sorting and culture identifies FLK1 + VEcadherin + cells at a diverging point of endothelial and hemopoietic lineages. Development 125, 1747-1757 (1998).

30. Nishikawa, S. I. et al. In vitro generation of lymphohematopoietic cells from endothelial cells purified from murine embryos. Immunity 8, 761-769 (1998).

31. Nakano, T., Kodama, H. \& Honjo, T. Generation of lymphohematopoietic cells from embryonic stem cells in culture. Science 265, 1098-1101 (1994).

32. Medvinsky, A., Taoudi, S., Mendes, S. \& Dzierzak, E. Analysis and manipulation of hematopoietic progenitor and stem cells from murine embryonic tissues. Curr. Protoc. Stem Cell Biol. Chapter 2, Unit 2A 6 (2008).

33. Taoudi, S. et al. Progressive divergence of definitive haematopoietic stem cells from the endothelial compartment does not depend on contact with the foetal liver. Development 132, 4179-4191 (2005).

34. Hirai, H. et al. Hemogenic and nonhemogenic endothelium can be distinguished by the activity of fetal liver kinase (Flk)-1 promoter/enhancer during mouse embryogenesis. Blood 101, 886-893 (2003).

35. Wilson, N. K. et al. Combinatorial transcriptional control in blood stem/ progenitor cells: genome-wide analysis of ten major transcriptional regulators. Cell Stem Cell 7, 532-544 (2010). 
36. Swiers, G., Patient, R. \& Loose, M. Genetic regulatory networks programming hematopoietic stem cells and erythroid lineage specification. Dev. Biol. 294, 525-540 (2006).

37. Wilson, N. K. et al. Gfil expression is controlled by five distinct regulatory regions spread over 100 kilobases, with Scl/Tal1, Gata2, PU.1, Erg, Meis1, and Runx1 acting as upstream regulators in early hematopoietic cells. Mol. Cell Biol. 30, 3853-3863 (2010).

38. Okada, H. et al. AML1(-/-) embryos do not express certain hematopoiesisrelated gene transcripts including those of the PU.1 gene. Oncogene 17, 2287-2293 (1998).

39. Emambokus, N. et al. Progression through key stages of haemopoiesis is dependent on distinct threshold levels of c-Myb. EMBO J. 22, 4478-4488 (2003).

40. Moignard, V. et al. Characterization of transcriptional networks in blood stem and progenitor cells using high-throughput single-cell gene expression analysis. Nat. Cell Biol. 15, 544 (2013).

41. Pina, C. et al. Inferring rules of lineage commitment in haematopoiesis. Nat. Cell Biol. 14, 287-294 (2012).

42. Mikkola, H. K., Fujiwara, Y., Schlaeger, T. M., Traver, D. \& Orkin, S. H. Expression of CD41 marks the initiation of definitive hematopoiesis in the mouse embryo. Blood 101, 508-516 (2003).

43. Ferkowicz, M. J. et al. CD41 expression defines the onset of primitive and definitive hematopoiesis in the murine embryo. Development 130, 4393-4403 (2003).

44. Nakano, H. et al. Haemogenic endocardium contributes to transient definitive haematopoiesis. Nat. Commun. 4, 1564 (2013).

45. Richard, C. et al. Endothelio-mesenchymal interaction controls Runx1 expression and modulates the notch pathway to initiate aortic hematopoiesis. Dev. Cell 24, 600-611 (2013).

46. Azcoitia, V., Aracil, M., Martinez, A. C. \& Torres, M. The homeodomain protein Meis1 is essential for definitive hematopoiesis and vascular patterning in the mouse embryo. Dev. Biol. 280, 307-320 (2005).

47. Kataoka, H. et al. Etv2/ER71 induces vascular mesoderm from Flk1 + PDGFRalpha + primitive mesoderm. Blood 118, 6975-6986 (2011).

48. Hirai, H. et al. Involvement of Runx1 in the downregulation of fetal liver kinase-1 expression during transition of endothelial cells to hematopoietic cells. Blood 106, 1948-1955 (2005).

49. Lichtinger, M. et al. Runx1 reshapes the epigenetic landscape at the onset of haematopoiesis. EMBO J. 31, 4318-4333 (2012).

50. Lancrin, C. et al. GFI1 and GFI1B control the loss of endothelial identity of hemogenic endothelium during hematopoietic commitment. Blood 120, 314-322 (2012)

51. Taoudi, S. et al. Extensive hematopoietic stem cell generation in the AGM region via maturation of VE-cadherin $+\mathrm{CD} 45+$ pre-definitive HSCs. Cell Stem Cell 3, 99-108 (2008).

52. Rybtsov, S. et al. Hierarchical organization and early hematopoietic specification of the developing HSC lineage in the AGM region. J. Exp. Med. 208, 1305-1315 (2011).
53. Livak, K. J. \& Schmittgen, T. D. Analysis of relative gene expression data using real-time quantitative PCR and the 2(-Delta Delta C(T)) Method. Methods 25, 402-408 (2001).

54. Gautier, L., Cope, L., Bolstad, B. M. \& Irizarry, R. A. Affy-analysis of Affymetrix GeneChip data at the probe level. Bioinformatics 20, 307-315 (2004).

55. Smyth, G. K. LIMMA: linear models for microarray data. in Bioinformatics and Computational Biology Solutions using $R$ and Bioconductor. (eds Gentleman, $\mathrm{R}$. Carey, V., Dudoit, S., Irizarry, R. \& Huber, W.) 397-420 (Springer, 2005).

\section{Acknowledgements}

We thank current and past members of the de Bruijn laboratory, in particular Stella Antoniou, Gonzalo Gomez-Tarragona and Charli Reynolds, for their practical help, Petter Woll and Adam Mead for their advice and discussions, Alexander Medvinsky and Emanuelle Passegue for helpful discussions, the Jessel lab for the Runxl antibody, Kevin Clark and Paul Sopp for expert flow cytometry, and staff at the Biomedical Services for animal care. This work was supported in Oxford by the MRC Molecular Haematology Unit core award and funding from the Leukemia and Lymphoma Research (UK), and in Cambridge by core support grants by the Wellcome Trust to the Cambridge Institute for Medical Research and Wellcome Trust \& MRC Cambridge Stem Cell Institute.

\section{Author contributions}

G.S. led the study, conducted and analysed the experiments, interpreted the experimental data, made figures and wrote the paper. C.B., J.O'R. and T.B. performed experiments and analysed data. E.G. performed bioinformatics analyses on single-cell Fluidigm data. S.T. and A.J. performed bioinformatics analysis on microarray data. C.P., V.M., T.E. and B.G. contributed to analysis and interpretation of single-cell Fluidigm data. G.S., K.D.K. and T.S. performed the E7.5 time-lapse imaging cultures and analysed the data, M.Y. and M.C.Y. provided protocols and assisted in establishing the OP9 co-culture system. J.F. contributed CD41-null mice. M.F.T.R.d.B. led and supervised all aspects of the study, performed embryo dissections, made figures and wrote the paper.

\section{Additional information}

Accession codes: Microarray data have been deposited at GEO database under accession number GSE2075.

Supplementary Information accompanies this paper at http://www.nature.com/ naturecommunications

Competing financial interests: The authors declare no competing financial interests.

Reprints and permission information is available online at http://npg.nature.com/ reprintsandpermissions/

How to cite this article: Swiers, G. et al. Early dynamic fate changes in haemogenic endothelium characterized at the single-cell level. Nat. Commun. 4:2924 doi: 10.1038/ ncomms3924 (2013). 